\title{
Bokko-chan $^{1}$
}

ボッコちゃん

\section{Autor: Shinichi Hoshi ${ }^{2}$ \\ Tradução e notas: Renan Kenji Hayashi ${ }^{3}$}

DOI: $10.19177 /$ memorare.v8e12021229-235

Resumo: 0 presente trabalho apresenta um gesto de tradução do conto de ficção científica Bokko-chan, do autor japonês Shinichi Hoshi (1926-1991). Trata-se de um dos primeiros escritos com essa temática no Japão, abrindo caminho para outros autores que explorariam posteriormente essa vertente. Embora o conto tenha uma grande relevância nos estudos literários japoneses, tendo sido traduzidos para várias línguas, o escrito ainda permanece inédito em português do Brasil. Dessa forma, apresentamos a seguir uma tradução dessa obra, desejando popularizar a leitura desse autor, bem como suscitar o interesse dos leitores para o restante de sua extensa produção literária.

Palavras-chave: Tradução Literária; Literatura Japonesa; Shinichi Hoshi; Ficção Científica Japonesa.

Abstract: This paper presents a translation of the sci-fi short story Bokko-chan written by the Japanese author Shinichi Hoshi (1926-1991). This is one of the first writings with this sci-fi theme in Japan, paving the way for other authors who would later explore this field. Although the tale has great relevance in Japanese literary studies, with translated versions into several languages, the short story still remains unpublished in Brazilian Portuguese. Thus, we present a translation of this work, wishing to popularize the reading of this author, as well as arouse the readers' interest for the rest of his extensive literary production.

Keywords: Literary Translation; Japanese Literature; Shinichi Hoshi; Japanese Science Fiction.

\footnotetext{
1 Optamos por deixar o título original em japonês, conferido pelo próprio autor no ato da escrita, uma vez que se trata de um nome próprio da personagem principal, acompanhado de um sufixo de tratamento relativamente comum em japonês.

2 Shinichi Hoshi (Tóquio, 1926-1991), autor japonês de ficção científica.

3 Professor Universitário (ESAMC). Doutor em Linguística Aplicada pela Universidade Estadual de Campinas (UNICAMP). Mestre em Linguística Aplicada pela Universidade de Brasília (UnB). Licenciado em Letras (UnB). Tradutor. renanhayashi@hotmail.com
} 
"Nunca se escreve nem na própria língua nem numa língua estrangeira" (DERRIDA, 1986, p.146). Derrida, ao nos deixar sem saída, no que diz respeito à natureza das línguas, nos convoca a pensar como operam os dispositivos de leitura-escrita entre línguas diversas e, sobretudo, pensar na tarefa do tradutor, outrora já problematizado por Walter Benjamin ([1921] 2013), em texto homônimo. Ao afirmar que não escrevemos na própria língua é porque esta língua não é nossa. Esta língua com a qual escrevemos, lemos, amamos, dizemos, conjuramos, mentimos, traduzimos, prometemos, ofendemos, esta língua não é nossa. Esta língua é do outro (DERRIDA, 1996). Ela vem do outro e ao outro nos conduz.

À vista disso, o trabalho do tradutor é, entre outras coisas, fazer com que a língua do outro funcione de tal maneira que possamos dizer coisas próprias, coisas nossas, coisas minhas lançando mão de um artefato que não é meu por excelência. Nesse sentido, ao tradutor cabe o papel de fazer com que um texto, com todos seus efeitos de sentido, funcione de uma língua à outra, sem perder os rastros de alteridade que compõem uma ou outra língua. Essa tarefa, por vezes ingrata, requer a sensibilidade de um profissional que deve, a despeito dos diversos gestos de violência que empreende no texto, preservar as marcas deixadas por um autor que pensou em si, pensou de si, em seu momento histórico-social, nas verdades do seu tempo - mesmo que seja para supera-las - e imprimiu em seu texto impressões que devem transparecer no movimento entre-línguas.

Como se não bastasse essa dificuldade, podem ocorrer diversos outros óbices à tarefa do tradutor. Como, por exemplo, a imaginação fértil e única do autor, que idealizando um futuro impossível, escreve como estrangeiro numa língua, cujo conteúdo é impossível de existir e ser vislumbrado em um certo recorte temporal. São os casos dos autores de ficção cientifica. Ao imaginarem um mundo utópico, um mundo outro, eles se valem da linguagem para dar vazão ao que eles têm de mais íntimo: a ideação. Contudo, quando essa ideação vem escrita em língua japonesa, temos aí uma dupla dificuldade incomensuravelmente mais árdua. É nesse contexto que localizamos nosso gesto de tradução do autor japonês Shinichi Hoshi (1926-1991).

Hoshi, autor de mais de mil escritos ao longo de vinte e seis anos de vida pública, é bastante popular no Japão por suas histórias de ficção científica, ou em um japonês 'adaptado', o chamado essu effu (as iniciais $\mathrm{SF}$, Science Fiction, em inglês). Hoshi escreveu muitas obras ditando um tom de essu effu nas décadas de 50 e 60, em um Japão do pós-guerra, cuja literatura ainda passava ao largo da temática que na Europa e nos Estados Unidos tinham proeminentes representantes, como Júlio Verne, H.G. Wells, Aldous Huxley e Harlan Ellison. De família muito abastada, Hoshi se forma na prestigiada Universidade de Tóquio em 1947, na área de Bioquímica. Entretanto, somente dez anos mais tarde, é que Hoshi começa a publicação de suas obras.

A Hoseki Magazine, em 1957, publica uma série com três de suas histórias, quais sejam: Sekisutora, Bokko-chan, Oi, Detekoi, dentre as quais, Bokko-chan, ora traduzida, é o mais famoso de seus textos. A 
partir desse momento, Hoshi alça a uma categoria de autor ficcional ainda muito incipiente no Japão, podendo lançar mão de elementos ainda pouco explorados na literatura do arquipélago. Ainda hoje, Hoshi figura como um dos mais importantes escritores de ficção do Japão. Ao lado de Kobo Abe, Hoshi é um dos autores mais lidos e traduzidos no mundo, embora pouquíssimo traduzido para língua latinas, com textos inéditos em língua portuguesa do Brasil.

À vista disso, o que apresentamos nas linhas que seguem é um gesto tradutório do conto Bokko-chan, que se encontra em domínio público nas bibliotecas e ambientes digitais. 0 que propomos a seguir é uma maneira de ler esse texto em português a partir do escrito em língua japonesa em contraste com a versão em língua inglesa do tradutor Noriyoshi Saito. A história ficcional à época, anos 50/60, nunca pareceu tão comum e atual para nós, leitores do século XXI. Contudo, a genialidade de Hoshi está exatamente aí, em imaginar - a partir de um Japão do pós-guerra, tentando curar suas feridas corporais e narcísicas um contexto absolutamente outro, com a tecnologia denunciando exatamente aquilo que não cessa de mostra ao homem sua finitude: a natureza demasiadamente humana dele.

Bokko-chan é também um texto relevante para um gesto tradutório por relevar aspectos muito particulares da cultura japonesa, como um certo fetichismo pelas máquinas e robôs, um decadentismo urbano que se desnuda perante uns copos de bebida, além da dificuldade imanente de contornar as demandas de relacionamento interpessoal, nas quais um robô que poderia se apresentar como a solução perfeita, causa, pelo contrário, a inversão de seu valor na sociedade japonesa urbana, podendo representar, inclusive, uma completa extinção da espécie. 


\section{Bokko-chan}

\section{Tradução do conto}

0 robô era realmente uma obra-prima. Era um robô feminino e, sendo artificial, fora projetada para ser a beleza perfeita. Cada elemento que compusesse uma garota encantadora havia sido levado em consideração. 0 problema era que ela parecia um pouco altiva ${ }^{4}$, mas quem é capaz de negar que um ar de altivez é um pré-requisito indispensável à beleza?

Ninguém mais havia ousado construir um robô desse tipo. De fato, era bobagem construir um robô só para fazer o trabalho de um homem, uma vez que, pelo mesmo preço, era possível projetar máquinas mais eficientes ou contratar trabalhadores adequados, em meio a muitos, cujas ofertas se abarrotavam nas colunas "Procuro Vaga" nos anúncios dos classificados.

No entanto, este robô fora feito por diversão pelo dono de um certo bar. Em geral, um dono de bar não bebe nada em casa. Para ele, as bebidas existe apenas como sua especialidade, que nunca deve ser consumida em benefício próprio. E aqueles bêbados obsessivos, que frequentavam seu bar, o ajudavam de bom grado a ganhar dinheiro, com o qual ele podia passar suas horas de descanso na persecução de um hobby.

Ocorre que seu hobby era a construção de uma robô atraente 5 .

Como esse era seu único passatempo, ele não poupava nem esforços, nem dinheiro para desenha-la. A saber: ela estava coberta com uma pele tão macia que dificilmente poderia ser distinguida daquela de uma garota real. Não é exagero dizer que ela era mais encantadora do que as belezas genuínas por aí.

Infelizmente, como muitas grandiosas beldades, ela era um tanto cabeça oca, já que a elaboração de um cérebro complexo estava além das capacidades de seu inventor. Ela era capaz de responder a perguntas de forma muito simples e realizar simples movimentos, como tomar uma bebida.

O dono do bar nomeou-a Bokko-chan e colocou-a em uma cadeira atrás do balcão de seu bar, a fim de que ela não ficasse perto demais dos clientes. Ele se ressentia que o robô pudesse mostrar o casco separado quando examinado de perto pelos clientes do bar.

Então, uma garota nova apareceu no bar e todos os visitantes a receberam com simpatia. Ela se comportava satisfatoriamente até que lhe perguntaram algo diferente de seu nome e idade. E ainda assim, felizmente, ninguém notou que ela era um robô.

\footnotetext{
${ }^{4}$ No original em japonês: つんつんと、高慢. Optamos pela sugestão de Noriyoshi Saito, em inglês, ao indicar um efeito de sentido como alguém 'prissy'. (N. do T.).

5 Aqui tem um efeito de sentido curioso: no original em japonês, Hoshi utiliza 美人 (びじ ん) - mulher atraente para caracterizar o robô. Nota-se, portanto, que é um tipo de adjetivo que deve caracterizar seres femininos. Noriyoshi Saito, em sua versão para o inglês, propõe um neologismo ao criar um substantivo feminino para caracterizar o robô. Assim, ao invés de 'robot', ele propõe 'robotness', como uma forma de diferir gêneros, o que ocorre em 'host' e 'hostess', masculino e feminino, por exemplo. Tentamos manter o efeito de sentido com o substantivo original, compondo o sintagma nominal com um artigo feminino apenas (N. do T.).
} 
- Qual é o seu nome, baby6?

- Bokko-chan.

- Quantos anos você tem?

- Eu ainda sou jovem.

- Bem, quão jovem você é?

- Eu ainda sou jovem.

- Eu digo, quão jovem você é?

- Eu ainda sou jovem.

Felizmente, os clientes do bar eram educados o suficiente para não continuarem com a questão da idade dela.

- Belo vestido que você veste, hein?

- Belo vestido que eu uso, não é mesmo?

- 0 que você mais gosta?

- 0 que eu mais gosto?

- Você vai beber um copo de ..., vamos dizer, gin fizz?

- Vou beber um copo de ..., vamos dizer, gin fizz.

Bokko-chan nunca se opôs a uma bebida. Mas também nunca se embriagou.

Encantadora, jovem, altiva e inteligente para conversar. A história da nova garota no bar se espalhou pelo bairro e o número de visitantes do bar aumentou. E todo visitante se divertia conversando e bebendo com a charmosa Bokko-chan. De fato, ela parecia agradar a todos.

- De quem você mais gosta entre nós?

- De quem eu mais gosto entre vocês todos?

- Você gosta de mim?

- Eu gosto de você.

- Bem, então, vamos ver alguns filmes?

- Quando nós vamos?

Sempre que perguntavam a Bokko-chan algo que ela não conseguia responder, ela sinalizava para o dono do bar que imediatamente corria para o lado dela.

- Ei, senhor, não é educado estar flertando tanto com um bebê desses ${ }^{7}$.

0 visitante insistente podia apenas sorrir e se retirar graciosamente sob a severa admoestação do dono do bar.

Por vezes, o dono do bar agachava-se ao pé de Bokko-chan, onde havia um pequeno cano de plástico instalado. Desse cano, ele drenava os coquetéis que ela havia bebido e, sendo um homem frugal, ele os servia novamente aos clientes. No entanto, os frequentadores do bar não estavam cientes disso e nunca deixavam de elogiar o robô em forma de mulher. Eles elogiavam sua juventude e beleza, seu caráter firme, o fato de que ela nunca se lisonjeou demais e que nunca se embriagou. Dessa forma, a popularidade e a fama da Bokko-chan cresceram demasiadamente, assim como o número de clientes do bar.

Entre os muitos admiradores de Bokko-chan estava um jovem cuja paixão por ela tornara-se tão grande que ele visitava o bar todas as

\footnotetext{
${ }^{6}$ No original em japonês: なまえは, portanto, não ocorre o uso de pronome de tratamento/adjetivo 'baby', bastante incomum em língua japonesa. Noriyoshi Saito inseriu em inglês, muito possivelmente, para conferir a atmosfera de informalidade e flerte que pode ocorrer em bares. Decidimos manter a sugestão de Saito (N. do T.).

7 No original em japonês: お客さん、あんまりからかっちゃあ、いけませんよう. Em japonês, há outro efeito de sentido. Contudo, manteremos a mesma textura conferida nos diálogos anteriores. Conferir nota no 6 (N. do T.).
} 
noites. Noite após noite, ele tentava convencê-la a sair com ele, sem sucesso algum. Sua falta de reação quase o deixou louco e ele acabou gastando muito mais do que podia pagar em um esforço para impressioná-la. Suas frequentes visitas ao bar fizeram com que ele acumulasse uma conta considerável e, quando o dono do bar o chamou para prestar contas, ele tentou roubar o próprio pai para pagar suas dívidas.

Seu pai o pegou em sua tentativa de furto, em uma cena difícil, durante a qual o pai concordou em adiantá-lo o suficiente para pagar suas dívidas, desde que ele prometesse nunca mais visitar o bar novamente.

Naquela noite, o jovem voltou ao bar para pagar sua conta e, sabendo que esta era sua última visita, bebeu muito e encarou Bokkochan.

- Eu não vou mais vir.

- Você não virá mais.

- Você está triste?

- Estou triste.

- Na realidade, você não está triste, está?

- Na realidade, eu não estou triste.

- Nenhuma outra garota é tão fria de coração quanto você.

- Nenhuma outra garota é tão fria quanto eu.

- Devo te matar?

- Você vai me matar?

O jovem tirou um pacote de remédios do bolso e os jogou no copo, depois empurrou o copo na direção de Bokko-chan.

- Você vai beber isso?

- Eu vou beber isso.

Bokko-chan ergueu o copo e esvaziou seu conteúdo.

- Vá para o inferno, vai? - disse o jovem.

- Eu vou para o inferno.

O menino rapidamente acertou sua conta com o dono do bar e saiu correndo pela noite.

Era quase hora de fechar e o dono do bar estava satisfeito por ter recebido uma dívida tão grande. Ele drenou a bebida de Bokko-chan e preparou bebidas para todos no bar.

- Bebam, homens - disse o dono do bar - esta é por minha conta.

Os fregueses do bar fizeram um brinde ao dono do bar, o qual ele agradeceu bebendo seu próprio copo.

Naquela noite, as luzes do bar não foram apagadas e o rádio continuou a tocar música. Ninguém foi embora e ninguém falava.

E chegou o momento em que o rádio disse "Boa noite" quando a estação saiu do ar.

- Boa noite - disse Bokko-chan, esperando com todo o seu ar altivo, pelo próximo homem a chama-la. 


\section{Referências}

BENJAMIN, Walter. 0 conceito de crítica de arte no romantismo alemão. São Paulo: Iluminuras, 2011.

BENJAMIN, Walter. A tarefa do tradutor. In: Escritos sobre mito e linguagem. São Paulo: Editora 34, 2013. p. 101-119.

DERRIDA, Jacques. Survivre. Journal de bord. In: DERRIDA, Jacques. Parages. Paris: Galilée, 1986.

DERRIDA, Jacques. Le monolinguisme de l'autre - ou la prothèse d'origine. Paris: Galilée, 1996.

DERRIDA, Jacques. Carta a um amigo japonês. Tradução Érica Lima. In: OTTONI, P. (Org.). Tradução - a prática da diferença. Campinas-SP: Editora da Unicamp; Fapesp, 1998.

HOSHI, Shinichi. Bokko-chan. In: APOSTOLOU, John; GREENBERG, Martin (Orgs.). The Best Japanese Science Fiction Stories. New York: Barricade Books, 1997. p. 47-52.

HOSHI, Shinichi (星 新一). Bokko-chan (ボッコちゃん). Tokyo: Shinchosha, 1963.

Tradução enviada em: 10/05/2021. Aprovada em: 15/06/2021. 